\title{
The survey of the information literacy among students and teachers
}

\author{
Kazuyuki Sunaga ${ }^{1}$
}

\begin{abstract}
The aim of my study is to research information literacy that university students and school teachers expect to acquire for themselves and to teach their students in Japan. Examining the questionnaire conducted to them, they are willing to acquire skills to identify their task, to read information, and to present the result of task. However, they are unwilling to acquire skills to evaluate the information that they have found, to make a note to be extracted from information resources, and to evaluate the process and performance. It is seemed that they are less interested in the instruction of evaluating information and making a note to their students. In future, as the explosive growth of information are continuing, it will be necessary that people master skills to evaluate information and to make a note. Teachers need to teach to their students not only skills to search and collect information but also skills to evaluate information and to make a note, and methods to evaluate process and performance.
\end{abstract}

Keywords: Information literacy, information skills, teachers, student, evaluation,

\section{Introduction}

\section{Information literacy in Japan}

This paper is intended as an investigation of the concepts of information literacy among university students and school teachers in Japan. This purpose of study is a new approach to the solution to the instruction of information literacy.

In the beginning, I would like to explain about the background of this study. The school library law was established in 1953 in Japan. We can find a school library in every school today. The most of schools have a computer room. However, a school library rarely connects with a computer room. In addition, there are a few of computers in a school library. As for the human resources, the staff of school library are two types; teacher librarian and school librarian. They don't always work in school library. Teacher librarians generally dedicate to teaching their subject in class room and sometimes work in school library. Teacher librarian can instruct information literacy. On the other hand, the school librarians are non-teacher staff. School librarians manage their school library but school librarians have few chances to teach information literacy. Because their roles are essentially clerical works. No person teaches information literacy in elementary schools. Technical art teachers in junior high school and information science teachers in senior high school often teach information literacy to their students while they instruct computer technology for one of the subject.

The policy of the Ministry of the Education, Culture, Sports and technology(MEXT) in Japan leads to increasing of school teachers' interest in the information literacy and the

\footnotetext{
${ }^{1}$ Kokugakuin University, Tokyo, Japan, sunaga@kokugakuin.ac.jp
} 
active learning. Their discussion concurrently focuses on the development of computer technologies and an increase of resources on webs. Unfortunately, they rather disregard the definition of information literacy and fundamental question of information skills remains still unanswered even though they often coped with the cross curriculum introduced in 2003. Because most of Japanese teachers and educators generally rely on textbook with teaching their subject in classroom and reluctantly agreed to do the cross curriculum. However, they face the educational policies relevant to information literacy.

More over two hundred universities and colleges in Japan provide the training courses for teacher librarians. In addition, 45 universities and the Open University of Japan provide summer session for uncertificated teachers. University students and trainees, who will take a certification of teacher librarian, do rarely realize the definition of information literacy as well. The programs in the course are so short that university students and trainees are unfamiliar with the information literacy. There are five subjects and ten credits during 150 hours in teacher librarian course. The training course consists of such subjects; the School management and school library, the Learning with school library, the Reading activities, the Organization of resources in school library and the Utilization of information media. They can learn information literacy in two subjects; the Learning with school library and Utilization of information media.

\section{The definition of information literacy}

It is inevitable that the definition of information literacy is considered. Olivier Le Deuff (2011), French researcher, discusses that information literacy(Informacy, Infoliteracy) is associated with computer literacy(IT/information technology / electronic information literacy), critical literacy (critical thinking), library literacy(library / bibliographic instruction), media literacy(new media literacy), network literacy(internet literacy, hyperliteracy), digital literacy(e-literacy), visual literacy and social literacy(participatory, media literacy, Participation literacy). Generally, the information literacy is ambiguous and the meaning is infinite.

Van Dijk and Van Deursen (2014) introduced the following range of skills concerning digital skills. 1. Operational skills, 2. Formal skills, 3. Information skills, 4. Communication skills, 5. Content creation skills, and 6. Strategic skills. They argued that less attention has been paid to so-called information skills, the ability to search, select, and evaluate information in digital media. As the explosive increase of information are progressing, the ability to select and evaluate information is crucial. When students become adults and work in society, it is important to explore, select and evaluate information. We will reflect the results of analysis in information literacy education.

Van Dijk and Van Deursen considered term "literacy" as referring to reading and writing text. In classical interpretation term "literacy" was meant to read sentences written on paper materials. In this paper, information literacy is considered as a range of skills to identify task, to search information, to read information, to evaluate information, to make a note, to present the result and to evaluate the efficiency of process and the effectiveness of performance. 


\section{Methods}

I added up the questionnaires among university students and school teachers. The questionnaire is consisted of three questions:

Question 1; What they did think of the information literacy before the training course or the practical training? They must choose one item from ten alternatives.

Question 2; Which skills they would like to acquire for themselves? They must choose three items from ten alternatives.

Question 3; Which skills they will teach to their students? They must choose three items from ten alternatives.

Question 1 means exactly what they imagined concerning information literacy before the training course for students or the practical training for teachers. Items in Question 1 are following; A. Computer, B. Internet, C. School library, D. Books, E. Periodicals or Magazine, F. Newspaper, G. News in radio or television and H. Others.

Items as information skills in Question 2 and 3 are based on the PLUS model published by James E. Herring in 1996.

Identifying their task includes brainstorming and concept-mapping to find their topics

Searching information

Reading information includes skimming and scanning

Evaluating information

Making a note extracted from information resources

Presenting the results

Self-evaluation includes the efficiency of process and the effectiveness of performance.

Using the PC and internet

Using library

Other things

A. Identifying their task is relevant to Purpose, B. Searching information is relevant to Location, C. Reading information, D. Evaluation information, E. Making a note, and F. Presenting the results are relevant to Use, and G. Self-evaluation is relevant to Self-evaluation in Herring's PLUS model. H. Using the PC and internet is relevant to Computer literacy mentioned by Le Deuff or Operational skills mentioned by Van Dijk and Van Deursen, and I. Using library is relevant to library literacy mentioned by Le Duff.

I conducted questionnaires to four groups; two groups of school teachers and two groups of university students. I show the demography of eligible persons. First group, teachers' group A was consisted of teachers in a municipal junior high school. A few teachers 
might be school library staff and most of them teach their subject in classroom. Second group, teachers' group B was consisted of teachers in public and private secondary schools and one member of local education board. Junior high school teachers accounted for $12 \%$, senior high school teachers accounted for $63 \%$, secondary school teachers accounted for $22 \%$, and member of local education board accounted for 3\%. As well as teachers' group A, most of group B teach their subject in classroom. Third group, students' group C was consisted of students who learned the subject called "learning activities and school library" in a private university in Tokyo. Forth group, students' group D was consisted students who learned the same subject in other private university in Tokyo. These students of two groups expected to become a teacher and they would like to be a teacher librarian. Table 1 shows demography of each group.

\section{Table 1}

Demography

\begin{tabular}{|c|c|c|c|c|c|c|c|c|c|}
\hline & & Gender & & Age & & & & & \\
\hline & & Female & Male & $18-19$ & $20-29$ & $30-39$ & $40-49$ & $50-59$ & $60-$ \\
\hline $\begin{array}{l}\text { Group } \\
(\mathrm{n}=26)\end{array}$ & $\mathrm{A}$ & $54 \%$ & $46 \%$ & -- & $19 \%$ & $12 \%$ & $27 \%$ & $38 \%$ & $4 \%$ \\
\hline $\begin{array}{l}\text { Group } \\
(\mathrm{n}=32)\end{array}$ & B & $45 \%$ & $55 \%$ & -- & -- & $35 \%$ & $13 \%$ & $52 \%$ & -- \\
\hline $\begin{array}{l}\text { Group } \\
(\mathrm{n}=36)\end{array}$ & $\mathrm{C}$ & $67 \%$ & $33 \%$ & $28 \%$ & $67 \%$ & $5 \%$ & -- & -- & -- \\
\hline $\begin{array}{l}\text { Group } \\
(\mathrm{n}=11)\end{array}$ & $\mathrm{D}$ & $73 \%$ & $27 \%$ & -- & $100 \%$ & -- & -- & -- & -- \\
\hline
\end{tabular}

In teachers in Group A and B filled in questionnaires after the practical training and workshop of information literacy. Furthermore, students in Group C and D filled in questionnaires within the last class of the subject called "learning instruction and school library". This subject is for the teacher librarianship.

\section{Analyses}

In regard of Question 1, the results indicated that school teachers in Group A and B regarded information literacy as computer as well as internet before the practical training. Most of the students in Group C and D considered information literacy to be something associated with the computer as well as internet rather school library before the training course. After the training course and the practical training, they regarded information literacy as a range of skills associated with libraries, computer and internet.

The following is to analyze the result of Question 2 and 3. The central problem of these questions is to clarify respondents' motivation to acquire information skills for themselves and to teach information skills to their students. Respondents' ability concerning information skills is too complicated to examine in detail. Because there remain many of abilities to examine and the criteria of information abilities is another matter. 
Figure 1 and 2 show school teachers' motivation relative to information skills. Red bars imply the skills they would like to acquire for themselves. Blue bars imply the skills they will teach to their students or pupils. It was found from Figure 1 and 2 that teachers in Group $\mathrm{A}$ and $\mathrm{B}$ expect to acquire for themselves the skills to search information and to present results of their task.

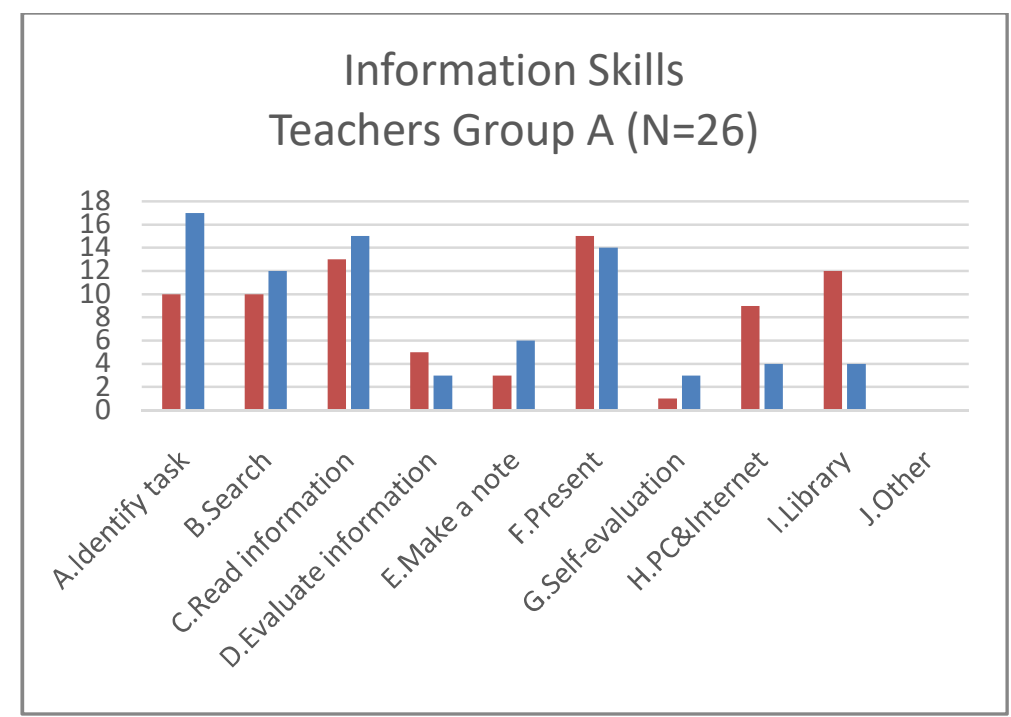

Figure 1. Information Skills Teachers Group A

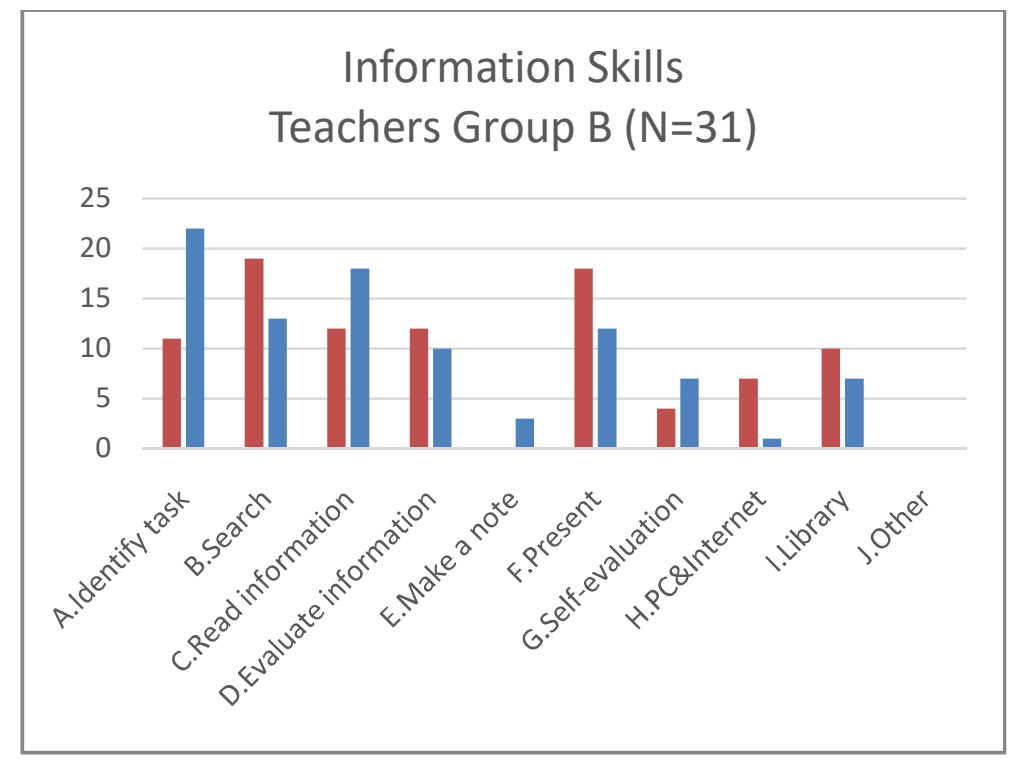

Figure 2. Information Skills Teachers Group B 
In Figure 3 and 4, as well as the charts of teacher groups, red bars imply the skills they would like to acquire for themselves, but only blue bars imply the skills they would like to teach to their students or pupils if they were a teacher in school. University students in Group $\mathrm{C}$ and $\mathrm{D}$ expect to acquire the skills to identify their task, to read information and to present results. University students in Group C expect to acquire a skill to search information and university students in Group D are unwilling to acquire a skill to search information in contradiction.

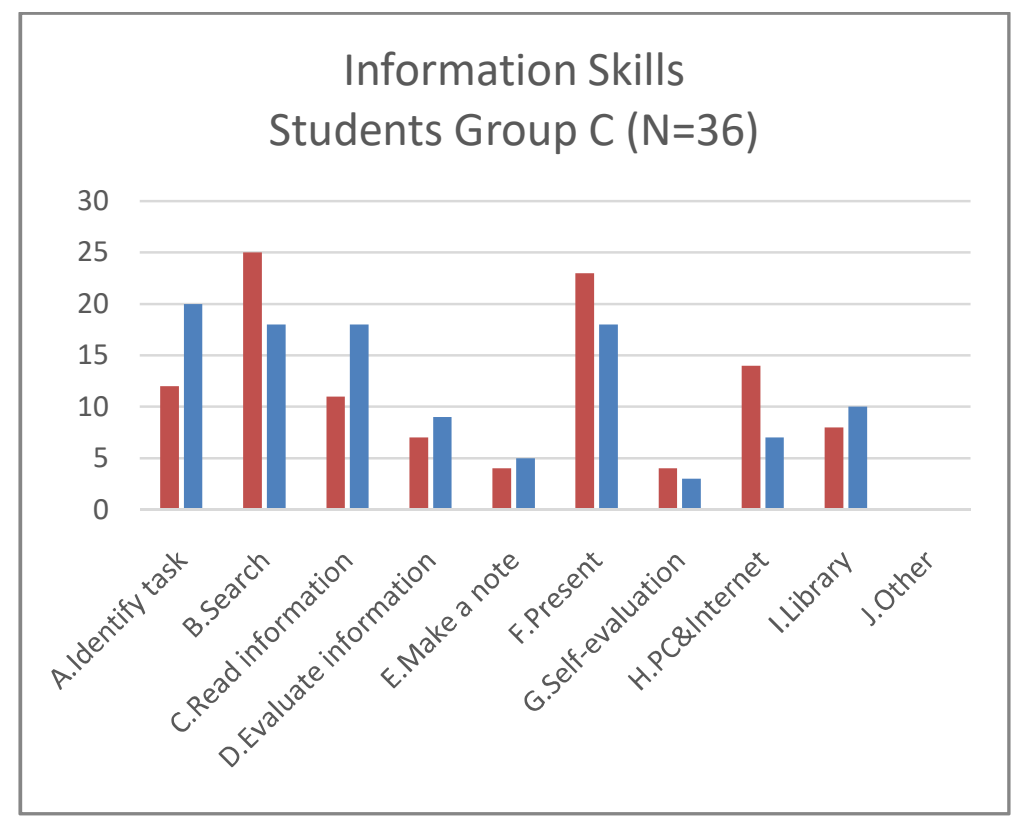

Figure 3. Information Skills Students Group C

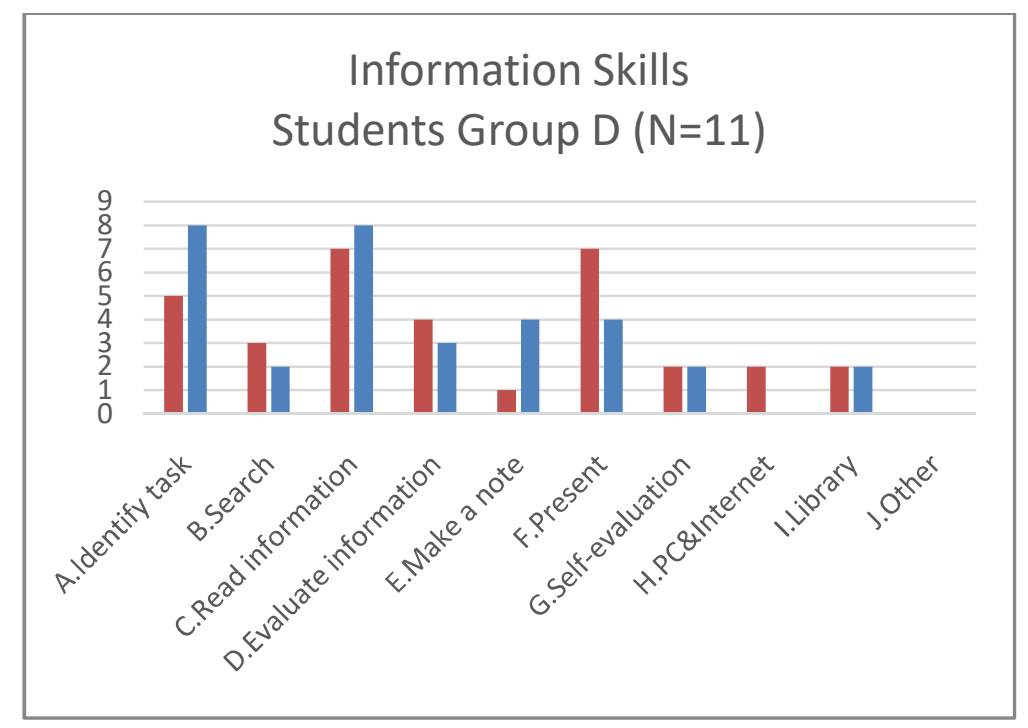

Figure 4. Information Skills Students Group D 
Relatively it was seemed that school teachers and university students are less interested in skills to evaluate information, to make a note extracted from information resources, and to evaluate the efficiency of process and the effectiveness of performance.

\section{Conclusion}

It is concluded that teachers and university students associate the information literacy with the internet and computer. It was seemed that they acquire the skills to identify task, to read information, to present results. They hope that their students/pupils will learn the skills to identify task, to search information resource, to read information and to present the results. School teachers and university students have a great interest in presentation skill. However, they are less interested in the skill to evaluate information, to make a note and to evaluate their task than other skills. Herring (2010) discussed that it is essential to teach students how to evaluate websites.

As the information on web is explosively increased in the future, we need to evaluate the meaning of information, to gain an insight into information and to struggle against fake news. We anticipate a potential need of the skills to evaluate information and to make a note extracted form information resource.

\section{References}

Herring, James E. (1996). Teaching information literacy skills in schools, London: Library Association.

Herring, James E. (2010). Improving Students' Web Use and Information Literacy a Guide for Teachers and Teacher Librarians, London: Facet Publishing.

Le Deuff, Olivier. (2011). La formation aux cultures numériques : une nouvelle pédagogie pour une culture de l'information à l'heure du numérique, (Limoges) : FYP.

Van Deursen, Alexander J. A. M. \& Van Dijk Jan A. G. M. (2014). Digital skills: unlocking the information society, New York: Palgrave Macmillan 